\title{
The Use of Polypropylene and High-Density Polyethylene on Cork Plastic Composites for Large Scale 3D Printing
}

\author{
F. Brites ${ }^{1, a^{*}}$, C. Malça $a^{2, b}$, F. Gaspar ${ }^{1, c}$, J.F. Horta ${ }^{1, d}$, M.C. Franco ${ }^{1, e}$, \\ S. Biscaia ${ }^{1, f}$, A. Mateus ${ }^{1, g}$ \\ ${ }^{1}$ Centre for Rapid and Sustainable Product Development, Polytechnic Institute of Leiria, Portugal \\ ${ }^{2}$ Department of Mechanical Engineering, Polytechnic Institute of Coimbra, Rua Pedro Nunes, \\ 3030-199 Coimbra, Portugal
}

afernando.mp.brites@gmail.com, bcandida@isec.pt, cflorindo.gaspar@ipleiria.pt, djoao.f.horta@ipleiria.pt, emargarida.franco@ipleiria.pt, 'sara.biscaia@ipleiria.pt, gartur.mateus@ipleiria.pt

\begin{abstract}
Keywords: 3D printing, composite, cork, CPC, PP, HDPE, mechanical and thermal properties, crystallinity.
\end{abstract}

\begin{abstract}
This work focuses on studying the possibility of $3 \mathrm{D}$ printing of composite materials composed by cork and a polymer matrix (CPC). Initially the cork was mixed with two types of polymers (HDPE and PP) in different proportions and later processed using extrusion and injection. The composites were tested to study the physical, chemical and mechanical properties. The material was then tested on a large-scale 3D printer to study its feasibility and the ability to produce new products through 3D printing. Attention was focused on the use of pure cork, varying the concentration of cork and coupling agent in thermoplastic matrix composites of PP and HDPE. It was demonstrated that the increase of $5 \mathrm{wt} . \%$ of coupling agent in the two types of polymers significantly improved the mechanical properties and adhesion between the phases but the increase in cork concentration decreased mechanical properties and crystallinity. The CPCs with PP showed to have better mechanical properties, better aesthetic and internal structural quality, and easier processability than those with HDPE matrix. Nevertheless, the HDPE CPCs showed a high degree of crystallization.

Concerning 3D printing, it was demonstrated the possibility of making new products based on natural cork fibers, showing promising results, although additional research is still needed to optimize the process.
\end{abstract}

\section{Introduction}

Cork is the bark of the Cork tree named Quercus suber L [1]. Cork is extracted periodically, usually every 9-12 years, depending on the region of cultivation. The cork tree has the advantage of being the only tree whose bark can regenerate after being extracted, making it a truly sustainable product [4]. The cork consists of a beehive of microscopic cells, filled with a gas similar to air and coated mostly by suberin and lignin [1].

The most important byproduct of cork processing is cork powder, which due to its calorific value is used as a raw material in industrial processes, and its monetary value is insignificant. There are several types of cork powders that have different characteristics, namely, grinding powder, granulation powder or pre-grinding powder, cleaning powder, the finishing powder from the cutting and sanding operations, and the "burning dust" that comes from the mixture of all these powders [4].

Cork has a combination of valuable properties for various applications and its combination with other materials can improve its performance. Cork combined with thermoplastic polymers has specific properties that can contribute to sustainability in the forestry sector, since they are renewable, recyclable and non-toxic materials $[4,5]$. Cork and plastic composites (CPCs) intend to combine the engineering properties of thermoplastics with the unique advantages of cork, such as impermeability, low density, fire resistance, low thermal conductivity, among others. [4]. 
The scientific community has been giving increasing attention to this type of composites, and in recent years there has been an increasing interest in the use of these materials mainly as a substitute of wood. Corticeira Amorim, one of the world's leading cork producers, has collaborated with scientific institutions to launch various studies aimed at combining cork with polymers to develop new materials. In one of these studies different percentages of thermoplastic polymer and cork were used and including coupling agents in order to promote adhesion between materials and improve their properties. The results showed the potential that these materials based on natural products have, in particular, improved impermeability, fire resistance, impact resistance and acoustic insulation properties $[1,2,4]$. Although showing promising characteristics, it has been demonstrated that improvements in stiffness and strength are still required, which can be improved by the addition of other coupling agents or even the combination of other natural polymers or fibers.

Nowadays, with the additive technologies growing, it would be very advantageous to use this type of materials in 3D printing. 3D printers work primarily with PLA and ABS, but new materials such as polymer blends and wood filaments have been increasingly implemented. This technology would allow cork-based products to develop faster than ever before, reduce production costs, create prototypes more easily, and produce parts with complex geometry. Furthermore, in environmental terms, energy-efficient technology would also be used and would enable the use of new materials in a sustainable way. Besides that, the carbon footprint would be reduced compared to products traditionally manufactured.

\section{Materials and Methods}

\section{Cork, polymers and coupling agents}

The cork powder resulting from the final stages of cork processing was collected at Amorim Cork Composites industrial facilities. The cork power had a particle size of $0.5-1 \mathrm{~mm}$. The polymers used as matrix were a high density polyethylene (HDPE KS10100) with an MFI of $4 \mathrm{~g} / \mathrm{min}^{-1}$ $\left(190^{\circ} \mathrm{C}, 2.16 \mathrm{~kg}\right)$ and a specific weight of $0.955 \mathrm{~g} / \mathrm{cm}^{3}$, and a polypropylene (PP070 G2M) with an MFI of $12 \mathrm{~g} / \mathrm{min}^{-1}\left(230^{\circ} \mathrm{C} ; 2.16 \mathrm{~kg}\right)$ and a specific weight of $0.905 \mathrm{~g} / \mathrm{cm}^{3}$. The coupling agent selected was a maleic anhydride modified HDPE (HDPE-g-MA) - Fusabond E265, having an MFI of $12 \mathrm{~g} / \mathrm{min}^{-1}$ and a $131{ }^{\circ} \mathrm{C}$ melting point supplied by DUPONT, and a maleic anhydride modified PP (PP-g-MA) - Exxelor PO 1020, with an MFI of $110 \mathrm{~g} / \mathrm{min}^{-1}$ and a $156{ }^{\circ} \mathrm{C}$ melting point provided by ExxonMobil, Germany. The thermoplastics were purchased from commercial companies operating in the Portuguese market.

\section{Composites Processing}

Cork powders were dried using an oven at $70^{\circ} \mathrm{C}$, in order to get similar moisture conditions on the processed materials. This procedure also ensures a better dimensional stability and improves the process since not all the cork contains the same moisture content and different moisture contents affect the final product to be developed.

The cork powder was mixed with the polymers using different proportions (Table 1) and compounded using a extruder machine (Werner \& Pfleiderer-ZSK25x38D) with a $25 \mathrm{~mm}$ diameter spindle, 1 main feeder, 1 side feeder, 1 degasser, a $10 \mathrm{~kW}$ motor and a maximum spindle speed of $300 \mathrm{rpm}$. In addition to these systems for mixing and extrusion, the machine is also constituted by a tank with rollers and water for material cooling and a system that allows cutting the material in order to obtain the CPC granules. Since cork begins to have a significant degradation at temperatures higher than $200^{\circ} \mathrm{C}[4,6]$ an extrusion temperature of $180^{\circ} \mathrm{C}$ was used.

Then the CPC granules were dried in the oven at $90^{\circ} \mathrm{C}$ and then injected using a proper machine (Boy 22A) designed for the automatic processing of thermoplastic materials, elastomers, silicones among other thermoplastic materials to produce the specimens needed for the mechanical testing. The specimens were obtained by using an injection mould at a temperature between $180^{\circ} \mathrm{C}$ and $195^{\circ} \mathrm{C}$ depending on the polymer and cork percentage. 
Table 1. Compositions of the cork polymer composites

\begin{tabular}{lcccc}
\hline Polymer type & $\begin{array}{c}\text { Cork } \\
\text { polymer } \\
\text { composite } \\
\text { type }\end{array}$ & $\begin{array}{c}\text { Cork } \\
(\text { wt. \%) }\end{array}$ & $\begin{array}{c}\text { Polymer } \\
\text { (wt.\%) }\end{array}$ & $\begin{array}{c}\text { Coupling } \\
\text { agent } \\
\text { (wt.\%) }\end{array}$ \\
\hline \multirow{5}{*}{ PP } & CPC1 & 15 & 83 & 2 \\
& CPC2 & 30 & 68 & 2 \\
& CPC3 & 15 & 80 & 5 \\
CPC4 & 30 & 65 & 5 \\
HDPE & CPC5 & 15 & 78 & 8 \\
& CPC6 & 30 & 62 & 8 \\
\hline CPC7 & 15 & 83 & 2 \\
& CPC8 & 30 & 68 & 2 \\
& CPC9 & 15 & 80 & 5 \\
CPC10 & 30 & 65 & 5 \\
& CPC11 & 15 & 78 & 8 \\
& CPC12 & 30 & 62 & 8 \\
\hline
\end{tabular}

\section{CPC density}

The density of the CPC granules obtained after extrusion was calculated on the basis of the Archimedes principle from which a partially or totally submerged object in a liquid, is subjected to a force, in the vertical direction, from bottom to top, and with intensity equal to the weight of the displaced liquid. Given that the cork has lower density than water, it would be difficult to measure the density using a pycnometer. Therefore, to perform the test, the cork was forced to submerge in the liquid using a capsule specially designed for this process. Five specimens were tested for each type of CPC granule.

\section{Wettability}

The degree of wetting (wettability) was determined using the contact angle test and the angle measured through the contact between the liquid and the CPC solid surface. The water contact angles measurements were performed with a Tensiometer Theta Lite TL100 equipment using a water droplet as the indictor. When measuring the contact angle of the sample a water droplet was first deposited by a syringe on the sample surface, and then the projection of the sessile droplet was captured to calculate the contact angle. Five measurements on each different specimen spots were made for each specimen.

\section{Tensile Tests}

The mechanical performance of the cork composites was evaluated through the tensile strength test. This test was conducted through a universal test machine Instron 4505. The machine is made of two spindles with ball bearings that allow the arm to move in the vertical direction ( $\mathrm{Z}$ axis), and of load and displacement sensors system in order to return values to which it is subjected to test a particular sample. The dimensions of the test pieces were in accordance with the standard ISO 5274. The dimensions of the specimens were $4 \mathrm{~mm}$ thick, $150 \mathrm{~mm}$ length and $20 \mathrm{~mm}$ width. The set of tests was conducted using a load cell with maximum capacity of $100 \mathrm{kN}$ and a crosshead speed of 2 $\mathrm{mm} / \mathrm{s}$. Five specimens were tested for each CPC type and all of them were loaded until the specimen failure. The results were analyzed regarding the maximum tensile stress and strain. The elastic modulus was obtained for all the specimens using the first 5 to 80 collected stress-strain data points, given that in the initial phase of the process the grips may not be properly adjusted to the sample resulting in a deviation of the initial measurements. 


\section{Thermal Analysis}

A STA 6000 (Perkin Elmer) equipment was used for thermal analysis of the materials. Samples of $6 \mathrm{mg}$ were placed in alumina pans and empty pans were used as reference. All samples were first heated at a range of $30-160{ }^{\circ} \mathrm{C}$ at a heating rate of $10^{\circ} \mathrm{C} / \mathrm{min}$ and held isothermally for $1 \mathrm{~min}$ to mitigate any prior thermal history. Afterwards, the samples were cooled to $30{ }^{\circ} \mathrm{C}$ at $10{ }^{\circ} \mathrm{C} / \mathrm{min}$ and then reheated to $160{ }^{\circ} \mathrm{C}$ at the same rate. After each test, the melting point region from the thermograph was analyzed to determine the heat of fusion $(\Delta H \mathrm{H})$ and the melting temperature $(\mathrm{Tm})$; the crystallization region was analyzed to determine the crystallization temperature (Tc) of all samples. To evaluate the thermal degradation of the materials, the samples were exposed to a temperature ramp from $30^{\circ} \mathrm{C}$ to $600^{\circ} \mathrm{C}$, at a heating rate of $10^{\circ} \mathrm{C} / \mathrm{min}$. The flow rate of nitrogen was $20 \mathrm{~mL} / \mathrm{min}$ during all the runs. The degree of crystallinity was calculated based on $100 \%$ crystalline HDPE and PP with enthalpies of $\Delta H m^{0}=293 \mathrm{Jg}^{-1}$ and $\Delta H m^{0}=209 \mathrm{Jg}^{-1}$ respectively, according to equation:

$$
X c(\%)=\left(\Delta H m /\left(\Delta H m^{0} \times(1-w)\right) \times 100\right.
$$

Where $\Delta H m$ is the melting enthalpy of the sample, $\Delta H m^{0}$ the melting enthalpy of the $100 \%$ crystalline polymer and $w$ the mass fraction of the cork in the composite.

\section{FTIR}

Fourier transformed infrared spectroscopy (FTIR) is a technique used to obtain an infrared spectrum of absorption or emission of a solid, liquid or gas. In this work this technique was used to identify the cork and the polymer in the composite spectrum. The spectra were obtained using an ATR Fourier transform infrared spectrometer (Alpha FT-IR spectrometer, Bruker, Belgium). The assays were run in a range of 4000 to $400 \mathrm{~cm}-1$ with a resolution of $4 \mathrm{~cm}-1$ and studied in triplicate.

\section{Morphological Tests}

The micro computerized tomography technique, known as Micro-CT, was used to study the internal structure of the cork composites produced. The Micro-CT allows to reconstruct a series of flat images in spatial configurations and in this way to internally visualize the structure of the materials under study. In order to study the internal structure of the cork composites, a Bruker SkyScan (1174v2) equipment was used with the following parameters: Voltage: $50 \mathrm{kV}$; Current: $800 \mu \mathrm{A}$; Pixel size: $11.23 \mu \mathrm{m}$; Exposure time: $3500 \mathrm{~ms}$; Rotation: 0.700 degrees; no filter. In order to analyze in more detail the microstructure of the CPCs produced, a model SEM equipment VEGA3 (Tescan, Chech Republic) equipped with EDX, provided by the University of Coimbra was used.

\section{D printing}

Taking into account the 3D printing technique and for the purpose of obtaining large parts a system adapted with a Roboplan Company Robot and a Dohle-Extruder extruder distributed by the company JMPTOOL was used. The Robotplan Robot arm is the HP20F model that has a load capacity of $20 \mathrm{Kg}$ allowing a wide range of applications. In order to be able to print with these equipments, the robot arm is attached to a base of $600 \mathrm{~mm}$ fixed to the floor for a greater amplitude of the arm. The extruder is driven through a position controller and the temperature setting is done by a separate controller. 


\section{Results and Discussion}

\section{Cork powders characterization}

Taking into account the results from Table 2, the CPCs show a decrease in density, with an increase in the percentage of cork from $15 \mathrm{wt} . \%$ to $30 \mathrm{wt} . \%$. As the concentration of cork increased, the amount of polymer in the composite was reduced, thus reducing its density, as it can be observed by comparing the density of the pure polymers (PP and HDPE) with the CPCs. The cork $\left(0.226 \pm 0.026 \mathrm{~g} / \mathrm{cm}^{3}\right)$ has a density much lower than the polymer $\left(0.905 / 0.955 \mathrm{~g} / \mathrm{cm}^{3}\right)$, which means that, with increasing concentration, the composite tends to have a lower density. Thus, with the increase of the amount of cork in the mixture, it is possible to obtain very light composite materials. It is also important to point out that the bulk density results may had been influenced, in part, by the coupling agent which, according to Fernandes et al.[1], may causes a small decrease in the density of the composite.

The standard deviation obtained in the various study materials was significantly high, resulting in a deviation from the mean of about $20 \%$. These results of standard deviation can be explained by the effects of the processing method, by the measurement method and also by the real percentage of cork present in each of the compositions under study. There may have been a decrease in the percentage of cork in the composite due to the accumulation of cork in the spindle and in the channels of access to the extruder spindle. The percentage of cork in the polymer could be also reduced due to the fact that the CPC granules have pores along the surface as a result of the processing method, which is sufficient for trapping air bubbles which greatly influence the obtained density results.

Table 2. HDPE, PP and CPC materials density results

\begin{tabular}{clccl}
\hline $\begin{array}{c}\text { Polymer } \\
\text { matrix }\end{array}$ & Material & Cork (wt.\%) & $\begin{array}{c}\text { Coupling } \\
\text { agent }(w t . \%)\end{array}$ & Density $\left(\mathrm{g} / \mathrm{cm}^{3}\right)$ \\
\hline & PP & 0 & 0 & $0.905\left(^{*}\right)$ \\
& CPC1 & 15 & 2 & $0.66 \pm 0.132$ \\
PP & CPC2 & 30 & 2 & $0.53 \pm 0.067$ \\
& CPC3 & 15 & 5 & $0.65 \pm 0.121$ \\
& CPC4 & 30 & 5 & $0.59 \pm 0.086$ \\
& CPC5 & 15 & 8 & $0.65 \pm 0.06$ \\
HDPE & CPC6 & 30 & 8 & $0.61 \pm 0.117$ \\
& HDPE & 0 & 0 & $0.905(*)$ \\
& CPC7 & 15 & 2 & $0.59 \pm 0.112$ \\
& CPC8 & 30 & 2 & $0.60 \pm 0.096$ \\
& CPC9 & 15 & 5 & $0.73 \pm 0.230$ \\
& CPC10 & 30 & 5 & $0.66 \pm 0.146$ \\
& CPC11 & 15 & 8 & $0.57 \pm 0.171$ \\
\hline
\end{tabular}

(*)Density of HDPE and PP withdrawn from the polymer Data Sheet

\section{Injection processing}

Looking at the aesthetic characteristics of the injected composites a more homogeneous distribution of the cork in the CPC with polypropylene polymer matrix can be observed. The CPCs with PP have a smooth brown surface in which it is possible to clearly observe the presence of the cork in the form of small grains of light brown color distributed regularly throughout the surface of the composite. In the case of the HDPE CPCs quite perceptible differences can be observed. They have a much darker brown color with signs of stretched polymeric material resulting in a much rougher surface. This aesthetic difference between the materials can be possibly due to the processing. During the injection process the materials were subjected to specific temperature and pressure. The PP samples were easy to process when compared to HDPE in which the parameter optimization was more difficult. One possible explanation for this behavior lies in the higher MFI of the PP compared to that of the HDPE. It is also important to note that in CPCs with both polymer 
matrix of HDPE and PP the increase in the cork percentage made it more difficult to obtain a complete part in the injection. In general, and taking into account the aesthetic characteristics and environmental concerns present in our day, cork can be considered as one of the candidate materials to be used in the development of sustainable materials [1].

\section{Wettability}

The injected specimens were subjected to a contact angle test in which a drop of liquid was placed on the surface of the injected composite to determine its relative humidity. Two different analyses were performed, initially a comparison of the contact angle was performed for the specimens with polymer matrix of PP and then the same test was performed for HDPE matrix.

Fig. 1 a) shows that the contact angle measurements are all below $90^{\circ}$, which means that the surface of the material has hydrophilic characteristics. Among of all CPCs tested the only one that approached the hydrophobic region was CPC4.

In Fig. 1 b), which represents the HDPE and HDPE CPCs, a very close contact angle values between them is shown. Only CPC7 and CPC10 presented the lower values. In these cases, unlike what happens with the CPCs with polymeric matrix of PP, there were no approximation of the hydrophobic region.
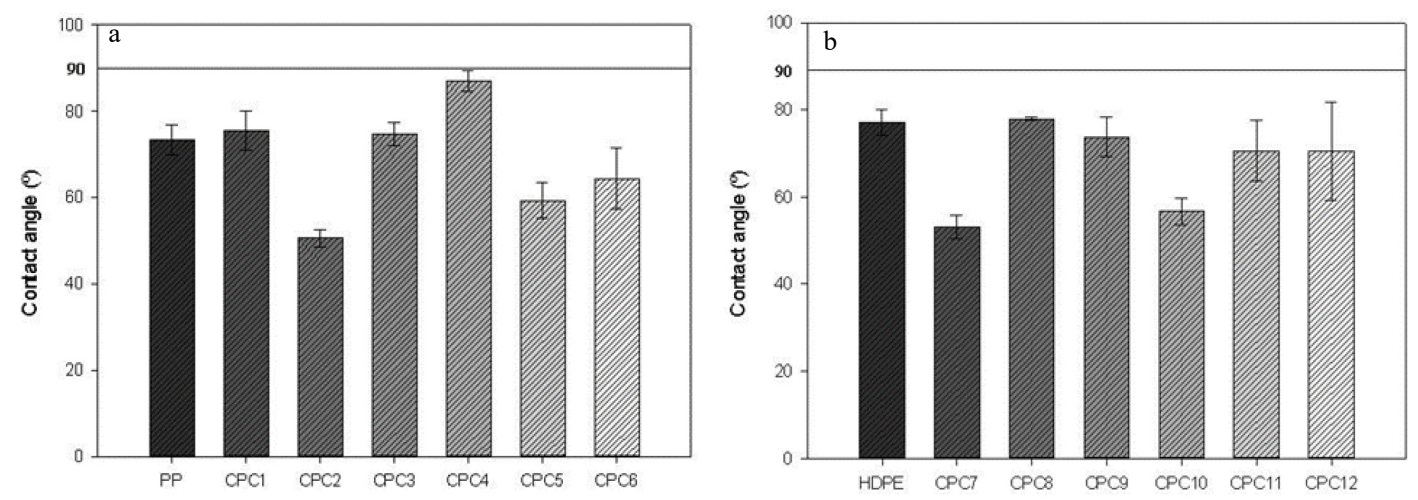

Fig. 1. Contact angle of: a) pure PP and PP CPCs; b) pure HDPE and HDPE CPCs

In both figures, Fig. 1 a) and Fig. 1 b), the materials under study have hydrophilic characteristics, despite both the polymer matrix and the reinforcement are hydrophobic materials [7]. Cork is impermeable to liquids and gases derived from its closely closed cell walls which are mostly suberin. However, it may exhibit some water permeability problems because it absorbs some moisture at room temperature. It has been previously reported that the contact angle of the cork is about $84^{\circ}$ but this value is reduced with time due to its permeability [1]. According to the literature once the moisture penetrates the cork, cork tends to swell up and as soon as the saturation period occurs can compromise the mechanical properties of the composite material. Thus, the addition of cork particles to the polymer results in a higher water absorption by the composites. According to Fernandes [2] it is possible that the hydroxyl and carboxylic polar groups present on the surface of the cork are responsible for the absorption of water. According with the author referenced, water absorption by lignocellulosic materials is partly due to the presence of small pores and hydrogen bonds present in bio components, spaces between interfaces or micro cracks caused during the extrusion process.

By analyzing the specimens presented in this study it was demonstrated that the polymer has created a superficial layer, incapsulating the cork grains inside. In this way the polymer has greater presence in the measurement of the contact angle since it covers the entire outer surface of the test piece. The fact that the polymers in the pure state are in the hydrophilic region influences the wettability of the remaining composites. This hydrophilicity behavior may arise from the processing conditions of the materials, in the present case from the injection process.

In relation to the addition of coupling agent, it wasn't possible to prove that it affects the surface of the material. Based on previous studies it is expected that the addition of the coupling agent 
alters the wettability behavior of the composite [1]. The groups of [-(CO)2O-] of the maleic anhydride interact with the hydroxyl groups present in the cork in order to increase adhesion and decrease the amount of polar groups on the surface of the composite, thereby reducing wettability [3]. Nevertheless, in this work it wasn't prove the influence of the coupling agent. Furthermore, the influence of the cork percentage on the contact angle measurements of the samples wasn't proved. This conclusion focuses more strongly on the CPCs with HDPE, since they presented a less homogeneous mixture of matrix and reinforcement.

\section{FTIR}

As a first analysis, looking at Fig. 2, it should be specified that it is not particularly important to analyze in detail the $\mathrm{CH}$ uptakes near the $3000 \mathrm{~cm}-1$ since almost all the composites have this type of absorptions. Looking at the spectrum this statement can be validated since all the materials under study have the same peaks in this zone. Although cork is mainly constituted by suberin there are in its composition several other compounds such as lignin and polysaccharides. Because cork is composed of several compounds, it becomes difficult it's spectrum analyses. In the cork spectrum it is possible to visualize a curve between the 3200 and $3600 \mathrm{~cm}^{-1}$ that is attributed to the axial deformation of the $\mathrm{O}-\mathrm{H}$ functional group characteristic of the hydrocarbons and the bonds of the lignin [8]. The cork spectrum has characteristic peaks of this type of material with the most intense peaks at $2918 \mathrm{~cm}^{-1}, 2850 \mathrm{~cm}^{-1}, 1735 \mathrm{~cm}^{-1}, 1242 \mathrm{~cm}^{-1}$ and $1160 \mathrm{~cm}^{-1}$ characteristic of the chemical bonds $\mathrm{C}-\mathrm{H}$ and $\mathrm{O}-\mathrm{C}=\mathrm{O}$. The peaks at $2918 \mathrm{~cm}^{-1}$ and $2850 \mathrm{~cm}^{-1}$ are related to suberin, cellulose, hemicellulose, low molecular weight composites and polysaccharides. It also presents a median band at $1508 \mathrm{~cm}^{-1}$ characteristic of chemical bonds of the lignin [2]. The cork spectrum can be visualized in Fig. 2 a).

In the case of pure polypropylene, the chains of molecules are composed of carbon atoms in the form of different groups. Each of them is represented in infrared spectroscopy spectra with absorption associated with wavenumber values (Fig. 2 b)). HDPE is essentially constituted by a chain of $\mathrm{CH}_{2}$ molecules which may have distinct configurations that vary depending on the region of the material (amorphous or crystalline). Looking at the HDPE spectrum two fairly high peaks in the region between 3300 and $2700 \mathrm{~cm}^{-1}$ corresponding to the $\mathrm{C}-\mathrm{H}$ functional groups (Fig. $2 \mathrm{c}$ )) can be observed. 

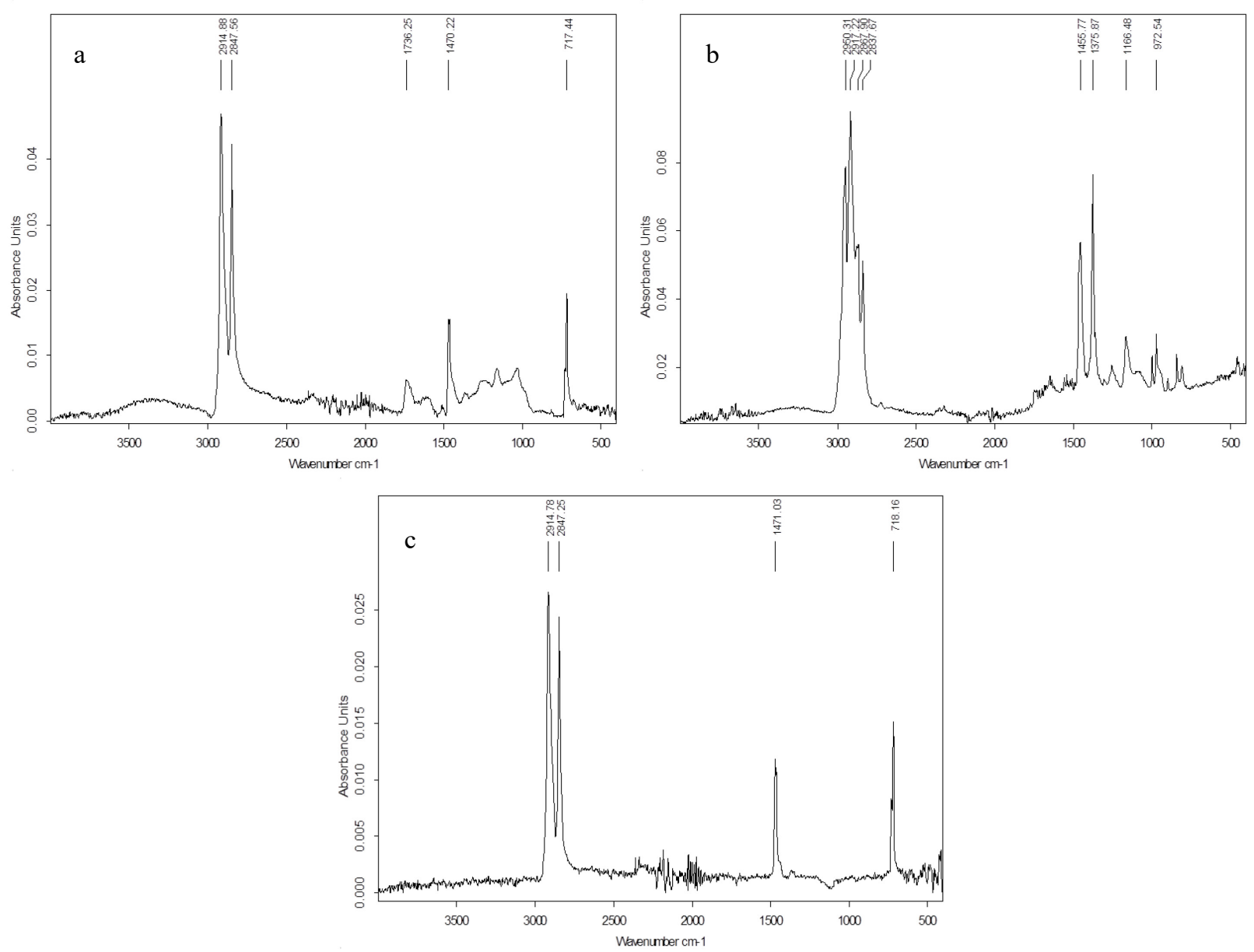

Fig. 2. FTIR spectra of a) cork; b) polypropylene; c) polyethylene

Looking at the emission spectrum of PP CPCs, represented in Fig. 3 a) and Fig. 3 b), a greater influence of the presence of polymer in the composite can be observed since it presents a spectrum similar to the pure polymer. This behavior may be due to the heterogeneous mixing of the material and the low percentage of cork. Each of the peaks in the spectrum is related to a particular binding, and some of the peaks present are common in both the matrix and the reinforcement, so it is normal to find the same peaks and thereby the same type of chemical bonds in the CPCs [9]. The cork presence is related to the peak referring to $1736 \mathrm{~cm}^{-1}$, which can be observed in both composites (CPC3 and CPC4). In the CPC3 the peak location is more difficult to observe due to the presence of higher noise in the spectrum.

The different spectra referring to the CPCs with HDPE matrix are represented in Fig. $3 \mathrm{c}$ ) and Fig. 3 d) where the presence of cork in the CPC emission spectrum can be seen. This assertion can be validated by looking at the $1736 \mathrm{~cm}^{-1}$ wavenumber peak, which is not present in the pure HDPE spectrum, but is presented in the cork spectrum. This peak may be due to a vibration stretch of the esters of the carbonyl groups $(\mathrm{C}=\mathrm{O})$, which may result from the esterification reaction between the $\mathrm{OH}$ groups of the cork and the functional groups of the polyethylene. These ester bonds can provide better wettability and dispersion, which in turn results in an improvement in the mechanical and thermal properties of the composites [2]. 

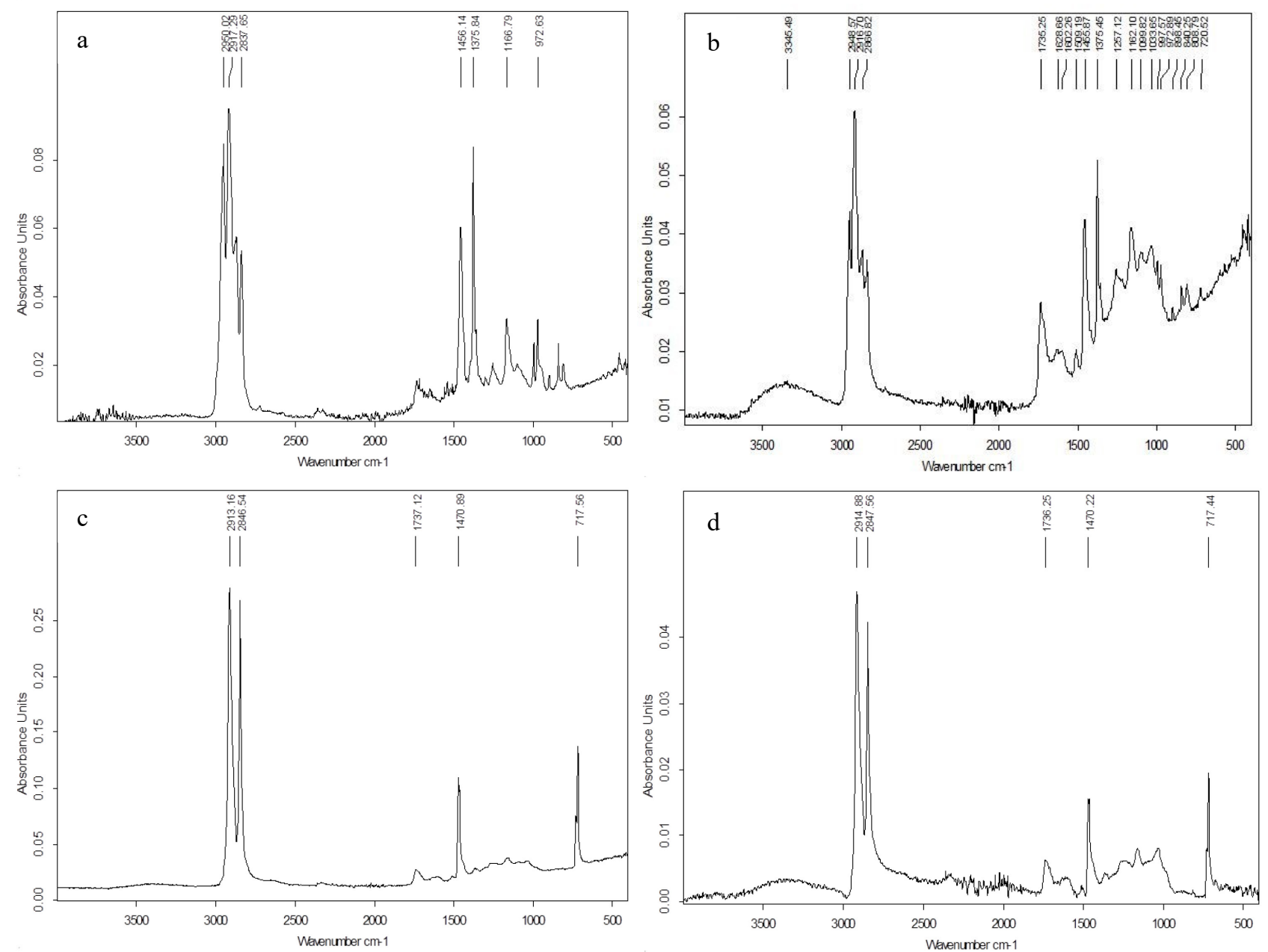

Fig. 3. FTIR spectra of Cork Polymer Composites: a) CPC3; b) CPC4; c) CPC9; d) CPC10

\section{Micro-CT}

The materials with the polymer matrix of PP and HDPE with higher mechanical strength were analyzed.

Based on the observation of the extruded PP polymer matrix composites, represented in Fig. 4 a) and Fig. $4 \mathrm{~b}$ ), the porosities in the center of the composite and in the zone of more compressed material next to the external walls can be visualized. This behavior of the material may be due to the release of gases generated during the process. One way to avoid this behavior it could be the assembly of an appropriate ventilation system with a vacuum or a devolatilization system in order to eliminate gases and residual products generated during the extrusion process [2].

It was not easy to distinguish cork particles from the polymer matrix through the resolutions obtained in the Micro-CT and therefore it's not possible through the images to draw conclusions about the interface between the two phases. However, a clear difference between the images relative to $15 \mathrm{wt} . \%$ and $30 \mathrm{wt} . \%$ of cork can be seen. The samples with $30 \mathrm{wt} . \%$ of cork have greater presence of porosities and a thinner outer wall.

By the observation of Fig. 4 c) and Fig. 4 d), that represent the tomographic images of the injected samples, a greater compression of the material than in the extruded filaments can be observed. However, it is also possible to visualize small openings or gaps throughout the sample, although they are significantly less that in the extrusion process. Between $15 \mathrm{wt} . \%$ and $30 \mathrm{wt} . \%$ of cork in the matrix it is possible to visualize a different configuration of the cracks having the samples of $30 \mathrm{wt} . \%$ a longer format and in those of $15 \mathrm{wt} . \%$ more rounded shape. Several factors may have led to this type of rheological behavior by the material such as molecular structure, weight and distribution of cork in the polymer. Other important parameters to consider are those 
related with the processing including temperature and pressure. It is also to be noted that the addition of cork to the polymer results in an increase in viscosity. An increase of $5 \mathrm{wt} . \%$ of cork to the polymer matrix of the PP can cause a reduction of about $50 \%$ of the MFI, revealing the tensions that occurred during the extrusion process [2]. The coupling agent may also play a very important rheological role. Maleic anhydride can act as a fluidity promoter of the material since it substantially improves the interface between the cork and the polymer. This behavior can be attributed to the lubricating / plasticizing effect of the coupling agent. In addition, the fact that the coupling agent has a structure similar to that of the matrix of the composite results in greater advantages in terms of compatibility.
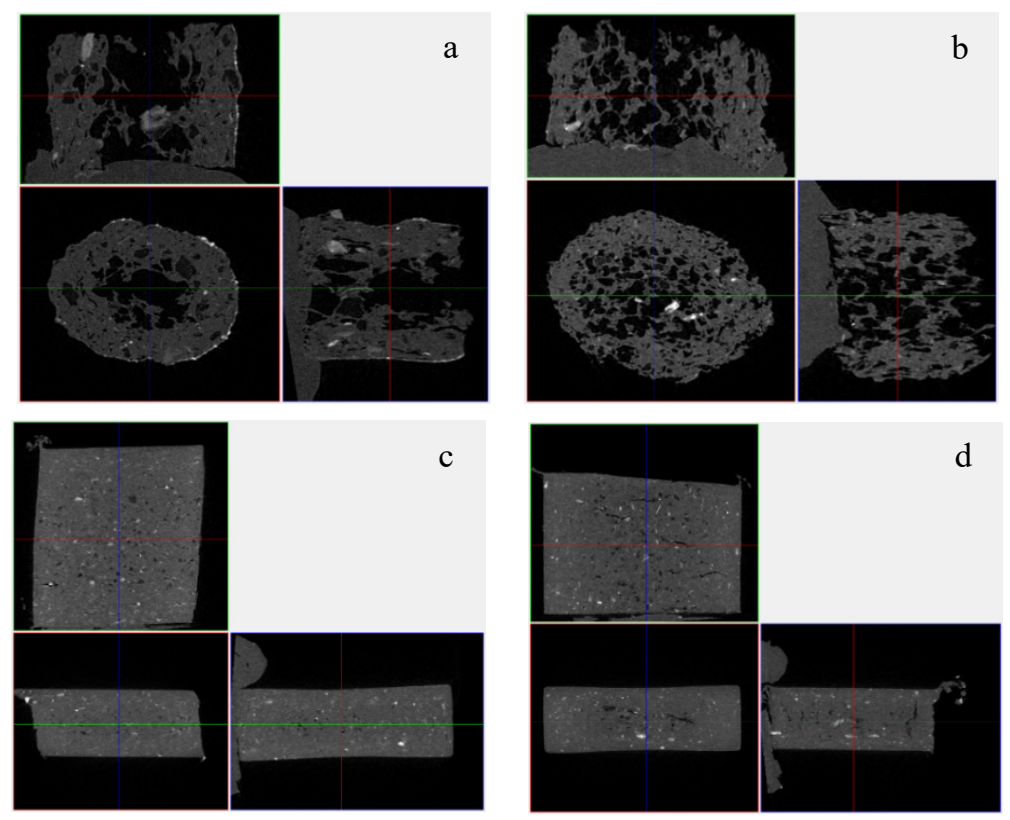

Fig. 4. Micro-CT of PP CPCs processed by: a) extrusion of CPC3; b) extrusion of CPC4; c) injection of $\mathrm{CPC} 3$; d) injection of CPC4

The HDPE polymer matrix CPCs depicted in Fig. 5, as in the previous ones with PP polymer matrix, shows very similar images in both: the injected and the extruded filaments, which leads us to believe that this type of behavior may be related with the interaction that occurs between the polymer and the cork during the process. During the extrusion process the low temperatures and pressures used do not allow the HDPE to flow as well as at higher temperatures and pressures in the injection process. In addition, the extrusion process can cause moisture absorption and shrinkage of the cork grains. These actions may result in voids at the interface between fiber and polymer, as well as cracks in HDPE [10]. 

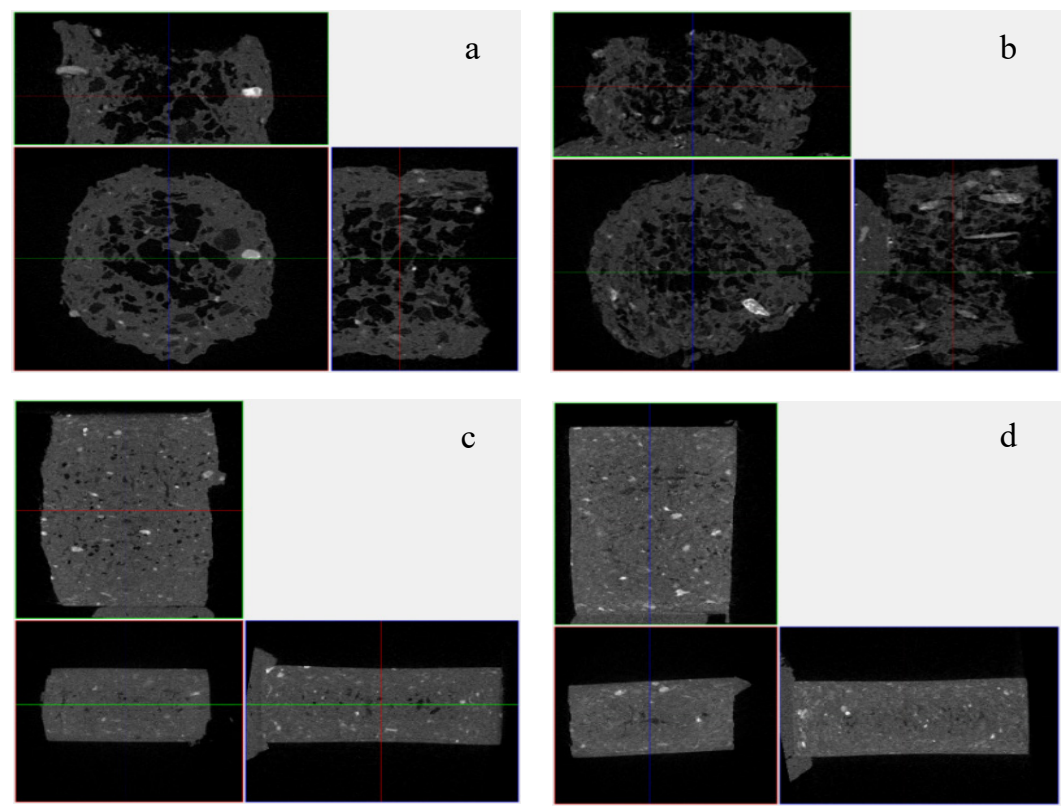

Fig. 5. Micro-CT of HDPE CPCs processed by: a) extrusion of CPC9; b) extrusion of CPC10; c) injection of CPC9; d) injection of CPC10

\section{SEM}

By observing the SEM images of Fig. 6, in a first analysis, a clear difference between the images of the samples obtained by extrusion and by injection can be observed. In the case of the samples processed by extrusion, represented in Fig. 6 a) and b), the presence of cork can clearly be distinguished by the small alveoli distributed regularly and compactly within the polymer matrix. For an image resolution of smaller magnification, it is possible to see the high quantity of cork present. Although only $15 \mathrm{wt} . \%$ of cork is added, the volume of the cork is significantly higher since the polymer has a specific mass almost 5 times higher than that of cork. The injected sample observed in Fig. 6 c) and d), on the other hand, presents a much more homogeneous distribution of the cork in the polymer matrix, being difficult to distinguish the different phases. A good interaction between the cork particles and the polymer matrix is demonstrated since empty spaces aren't seen.

It is also important to note that the distribution of the cork, especially in the extruded samples, is not homogeneous in part due to its processing. In the case of the injected samples this problem is much smaller since the processing method allows a higher compression. Even so, variations of the composition from zone to zone can influence its SEM analysis.

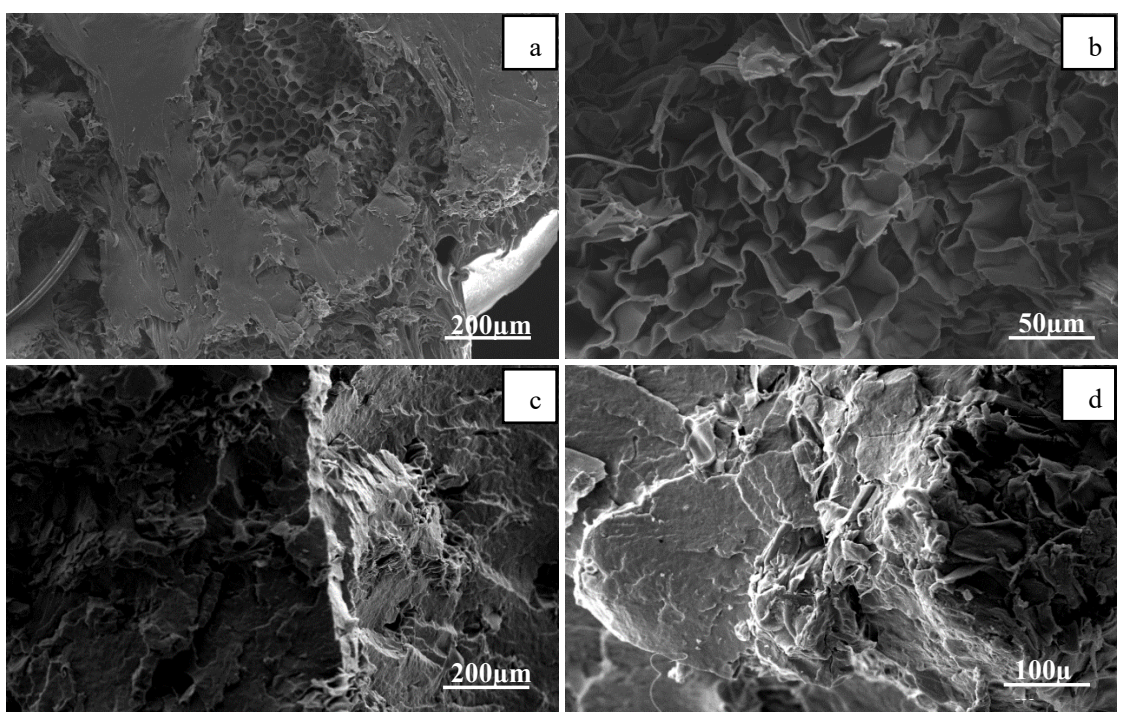

Fig. 6. SEM of CPC1 processed by: a) and b) extrusion; c) and d) injection 
Regarding Fig. 7 some differences with the increase of the coupling agent from $2 \mathrm{wt.} \%$ to $5 \mathrm{wt} . \%$ of PP-g-MA must be commented. In the case of the extruded sample observed in Fig. 7 a) and b), as in the previously studied extruded sample, the structure of the cork and the polymer matrix as two separate materials can be observed as a resulting of the heterogeneous distribution of the phases. In relation to the injected material represented in Fig. $7 \mathrm{c}$ ) and d) there are quite perceptible differences comparing with the sample injected with 2 wt.\% of PP-g-MA, evidencing a good but not so evident distribution of the cork in the polymer matrix. In addition, concerns to the cork distribution, its elasticity and adhesion to the polymer structure itself can be also observed. Maleic anhydride coupling agent is an important factor to consider since it interacts with polar cork groups (mostly lignin and hemicellulose $(\mathrm{OH})$ groups) to form covalent bonds or hydrogen bonds resulting in an improved chemical affinity and therefore increasing adhesion between phases. Furthermore, to changing the aesthetic appearance of the composite itself it also reduced the amount of voids and promote a better homogenization of the interface between the matrix and reinforcement.

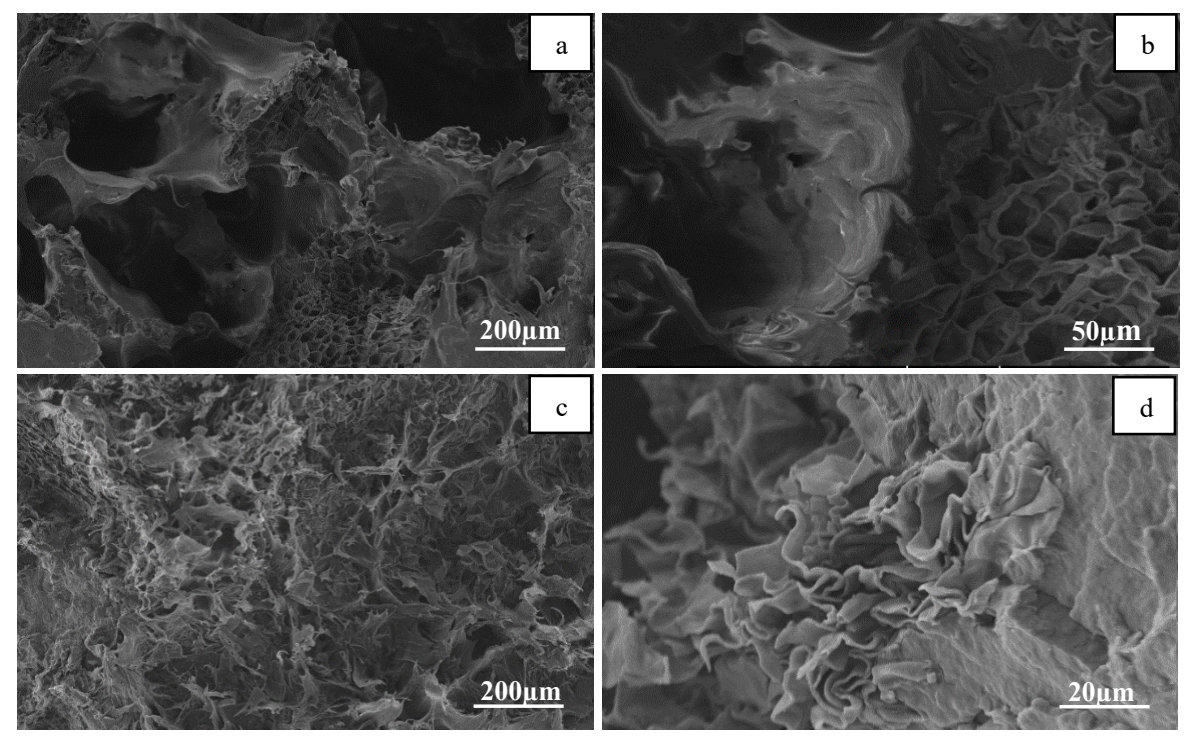

Fig. 7. SEM of CPC3 processed by: a) and b) extrusion; c) and d) injection

In the case of the CPC with 8 wt.\% of PP-g-MA, Fig. 8 shows some differences compared to the previous composites under study. In a first analysis an increase in the adhesion between the materials in the extrusion sample can be seen, especially if the resolution of greater magnification, as observed in Fig. 8 a) and b). The polymer seems to interact better with the structure of the cork presenting a more homogeneous surface. In the case of the injected sample observed in Fig. $8 \mathrm{c}$ ) and d) it is possible to differentiate the cork structure of the polymer even in resolutions with smaller magnification. This is corroborated by the mechanical tests results where the sample of $8 \mathrm{wt} \%$ of coupling agent had lower mechanical strength than the 5 wt.\% sample (Fig. 11 a)). An excessive addition rate of coupling agent may compromise the interface between the bio material and the polymer as it too closely approximates the hydrophilic surface polymer of cork by reducing the mechanical properties of the composite [2]. 

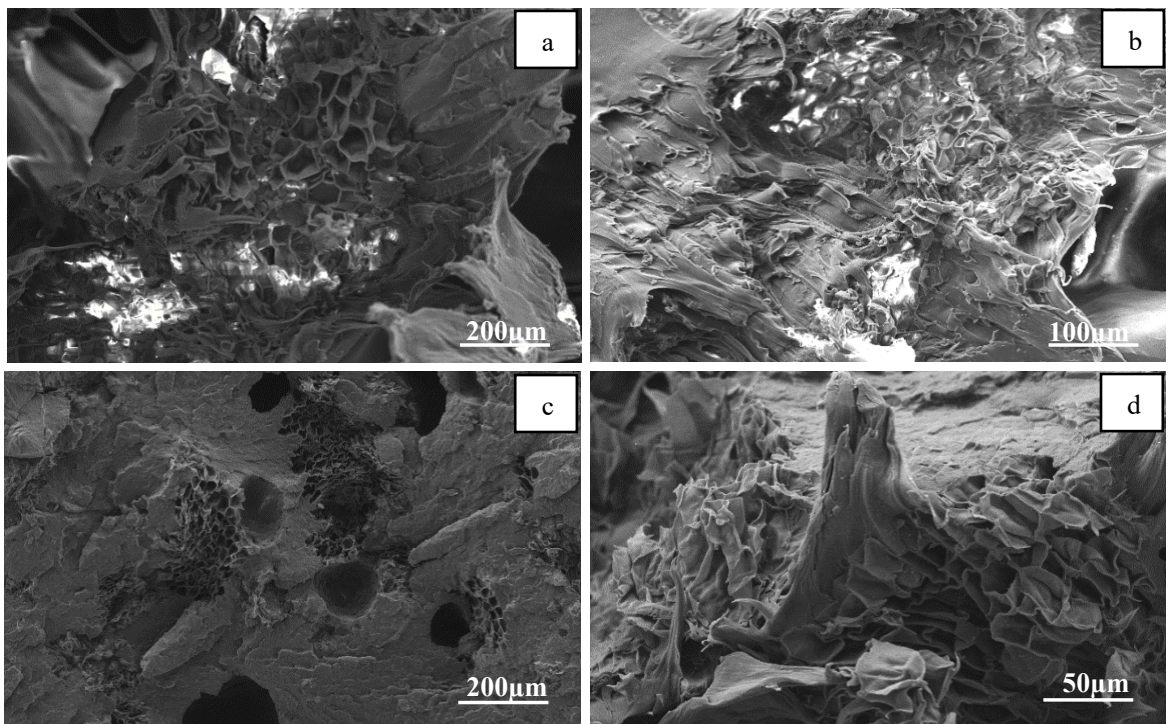

Fig. 8. SEM of CPC5 processed by: a) and b) extrusion; c) and d) injection

In the CPC with HDPE polymer matrix, shown in Fig. 9, it is possible, for both the extrusion and the injection samples, to visualize the presence of the cork. Although in the extrusion it is more difficult to show its presence, it can be noticed the existence of a surface with enough empty spaces to seriously compromise the resistance of the material as observed in the sample represented in Fig. 8 a). In relation to the injected sample, depicted in Fig. 9 c) and Fig. 9 d) the cork and the polymer can be clearly distinguished and the poor adhesion between the reinforcement and the matrix must be noted.

Although in both composites (CPCs of PP and HDPE) it is possible to observe a stretch of the polymer around the cork cells reducing the voids between the different phases, the CPCs with polymeric matrix of PP seem to have a more homogeneous distribution of the cork and greater adhesion to the polymeric matrix.

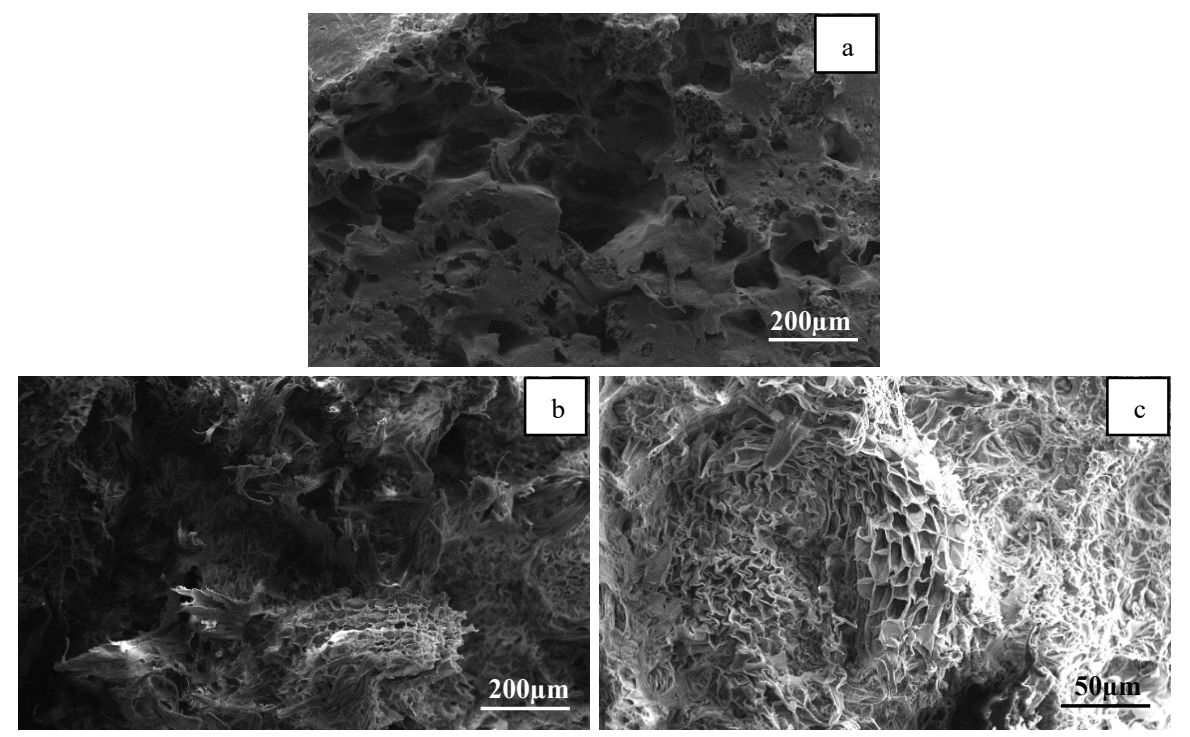

Fig. 9. SEM of CPC9 processed by: a) and b) extrusion; c) and d) injection

\section{Thermal Analysis}

The composite temperatures (melting, crystallization, polymorphic transitions, reactions, glass transition) and their thermal stability were investigated by DSC/TGA tests. All relevant results concerning the study materials are summarized in Tables 3 and 4. 
The pure PP has a crystallization temperature $(\mathrm{Tc})$ of $109.0^{\circ} \mathrm{C}$. Comparing the pure $\mathrm{PP}$ with the PP CPCs the Tc changed to slightly higher temperatures. The increase in Tc may be due to the nucleating effect of the cork present in the composites.

Table 3 also shows the melt temperature (Tm) of the PP, which is at $157.40^{\circ} \mathrm{C}$. The melting temperature of the composites was not significantly affected by the addition of cork which means that the addition of cork to the PP matrix does not have a great influence on the thickness of the crystalline lamellae of the polymer [4].

The values of $\Delta \mathrm{Hm}$ provide important information about crystallinity and show significant variations in the composites. These results lead to the conclusion that increasing the cork concentration from 15 wt. $\%$ to $30 \mathrm{wt} \%$ decreases the crystallinity of the polymer in most compositions, except in the composites with concentrations of $8 \mathrm{wt} . \%$ of PP-g-MA. The decrease in crystallinity may be related to the increase of the amorphous zones associated with the increased cork concentration in the composite.

Concerning the coupling agent, the results suggest that its addition contributes to the CPCs crystallization decrease. This behavior is not in agreement with the results obtained by Fernandes et al. [1] and Silva et al. [11] which suggest that the increase of the concentration of PP-g-MA in the blend is linked to a higher crystallization. The increased crystallinity may depend on the degree of compatibility between the polymer matrix and the cork as well as a heterogeneous mixture of phases, which can severely compromise the results obtained.

The TGA analysis shows that the onset of thermal degradation of the CPCs occurs between $436^{\circ} \mathrm{C}$ and $439^{\circ} \mathrm{C}$ with mass losses between $92 \%$ and $96 \%$. The DTG gives an idea of the decomposition temperatures (Tmax) of the materials under study. CPCs, in general, showed higher degradation temperatures than pure $\mathrm{PP}$, that is, the polymer matrix tends to decompound faster than the cork components. The cork confers a thermal barrier to the thermoplastic matrix at elevated temperatures due to the presence of lignin, which provides a higher thermal resistance. Thus, the addition of cork to the PP matrix increases the thermal stability of the polymer.

Table 3. Thermal properties of tested PP and CPC samples with PP

\begin{tabular}{|c|c|c|c|c|c|c|c|c|}
\hline & & $\mathbf{P P}$ & CPC1 & СРC2 & СРC3 & $\mathrm{CPC4}$ & CPC5 & СРС6 \\
\hline \multirow{4}{*}{$\begin{array}{l}\text { D } \\
\text { S } \\
\text { C }\end{array}$} & $T_{c}\left({ }^{\circ} \mathrm{C}\right)$ & $109,09 \pm 0,13$ & $111,18 \pm 0,89$ & $110,46 \pm 0,40$ & $110,78 \pm 0,33$ & $111,26 \pm 0,45$ & $110,58 \pm 0,43$ & $112,61 \pm 0,36$ \\
\hline & $T_{m}(\circ \mathrm{C})$ & $157,40 \pm 0,26$ & $158,91 \pm 1,08$ & $159,87 \pm 0,36$ & $160,33 \pm 0,514$ & $160,19 \pm 0,42$ & $160,69 \pm 0,96$ & $159,95 \pm 0,19$ \\
\hline & $\begin{array}{c}\Delta H m \\
(\mathrm{j} / \mathrm{g})\end{array}$ & $65,07 \pm 3,45$ & $44,98 \pm 2,71$ & $31,45 \pm 3,78$ & $39,99 \pm 7,65$ & $30,09 \pm 12,33$ & $29,53 \pm 3,83$ & $25,36 \pm 2,75$ \\
\hline & $X_{c}(\%)$ & 31,1 & 25,3 & 21,5 & 22,5 & 20,6 & 16,6 & 17,3 \\
\hline \multirow[b]{2}{*}{$\begin{array}{l}\mathbf{T} \\
\mathbf{G} \\
\mathbf{A}\end{array}$} & $\begin{array}{c}\mathbf{T}_{\text {on }} \\
(\circ \mathrm{C})\end{array}$ & $432,51 \pm 1,66$ & $439,11 \pm 0,61$ & $436,20 \pm 0,37$ & $439,11 \pm 0,37$ & $438,36 \pm 0,7$ & $438,94 \pm 1,14$ & $437,66 \pm 0,14$ \\
\hline & $\begin{array}{c}\text { Mass } \\
\text { loss } \\
(\%) \\
\end{array}$ & $98,91 \pm 0,43$ & $96,93 \pm 0,14$ & $93,03 \pm 1,43$ & $95,25 \pm 0,85$ & $93,09 \pm 0,25$ & $95,18 \pm 0,35$ & $92,43 \pm 0,31$ \\
\hline $\begin{array}{l}\text { D } \\
\text { T } \\
\text { G }\end{array}$ & $\begin{array}{l}T_{\max } \\
(\circ \mathrm{C})\end{array}$ & $454,89 \pm 0,46$ & $465,69 \pm 1,94$ & $469,66 \pm 0,59$ & $467,95 \pm 1,78$ & $470,96 \pm 0,74$ & $467,71 \pm 0,4$ & $470,54 \pm 0,94$ \\
\hline
\end{tabular}

Table 4 shows for the HDPE a crystallization temperature (Tc) of $112.23{ }^{\circ} \mathrm{C}$. Comparing pure HDPE with HDPE CPCs, the Tc varies according to the composite under study. The composites related to $\mathrm{CPC} 7$ and $\mathrm{CPC} 10$ have a slight increase of Tc and the degree of crystallinity $(\mathrm{Xc})$, that is, the presence of cork in these composites promotes crystallization. This behavior is attributed to the nucleating effect of cork [5]. From these results it can be concluded that the CPCs have a higher crystallinity $(\mathrm{Xc})$ than the pure polymer.

Table 4 shows too the melting temperature (Tm) of the HDPE, which is at $133.28{ }^{\circ} \mathrm{C}$. It can be observed that the melt temperature of the composites was not affected in relation to the pure polymer with the addition of $15 \mathrm{wt} \%$ of cork, for CPC7 and CPC11. On the other hand, the increase in the cork concentration from $15 \mathrm{wt} . \%$ to $30 \mathrm{wt} . \%$ increased Tm (CPC8, CPC10 and CPC12). 
The addition of $15 \mathrm{wt} \%$ of cork to HDPE resulted in increased crystallinity. A possible explanation for this observation may be related to the formation of new crystalline zones around the cork particles, through a spherulitic crystallization of the surface [2]. On the other hand, the increase in cork concentration, from $15 \mathrm{wt} . \%$ to $30 \mathrm{wt} . \%$, decreased the degree of crystallinity in all compositions, which may be related to the increase in the promoted amorphous zones by the increased concentration of cork.

In relation to the coupling agent, in the composites with addition of $15 \mathrm{wt} \%$ of cork (CPC 7, CPC9 and CPC11), the concentration increases in the mixture, from $2 \mathrm{wt} . \%$ to $5 \mathrm{wt} . \%$ of HDPE-gMA, did not contribute to an increase in crystallization. From 5 wt. $\%$ to 8 wt. $\%$ of HDPE-g-MA an increase in crystallization was verified. For the addition of $30 \mathrm{wt} \%$ of cork (CPC 8, CPC10 and CPC12), the crystallization behavior was also not linear, increasing from $2 \mathrm{wt} . \%$ to 5 wt. $\%$ of HDPE-g-MA and decreased from 5 wt. $\%$ to 8 wt.\% of HDPE-g-MA. In general, comparing CPCs with the pure polymer, the results obtained are in agreement with those pointed out by previous studies, which suggest that the crystallization of maleic anhydride based coupling agents is faster than in the pure polymer, due to the possibility of branching of the maleic anhydride polymer chains and better distribution in the polymer matrix [1].

The TGA analyzes suggest that the onset of thermal degradation of the CPCs with HDPE is distinct for each composite under study. In most compositions the degradation starts earlier than in pure polymer, except in the case of CPC11. It is also important to point out that, and only in the case of CPC8, the addition of $30 \mathrm{wt} . \%$ of cork promoted an increase in the temperature of onset of degradation.

The DTG allows to know the decomposition temperatures (Tmax) of the materials under study. HDPE CPCs, in general, showed degradation temperatures between 481 and $487^{\circ} \mathrm{C}$. The increased cork concentration in the blend decreased the loss of mass in all compositions.

Table 4. Thermal properties of tested HDPE and CPC samples with HDPE

\begin{tabular}{|c|c|c|c|c|c|c|c|c|}
\hline & & HDPE & CPC7 & CPC8 & СРC9 & CPC10 & CPC11 & CРC12 \\
\hline \multirow{4}{*}{$\begin{array}{l}\text { D } \\
\text { S } \\
\text { C }\end{array}$} & $T_{c}\left({ }^{\circ} \mathrm{C}\right)$ & $112,23 \pm 0,82$ & $114,14 \pm 1$ & $109,767 \pm 0,50$ & $111,49 \pm 0,75$ & $109,99 \pm 0,61$ & $113,9 \pm 0,26$ & $110,18 \pm 0,54$ \\
\hline & $T_{m}(\circ \mathrm{C})$ & $133,28 \pm 0,54$ & $133,37 \pm 1,12$ & $138,07 \pm 0,3$ & $137,17 \pm 0,40$ & $137,67 \pm 0,51$ & $133,54 \pm 0,75$ & $137,78 \pm 0,47$ \\
\hline & $\Delta H m(\mathrm{j} / \mathrm{g})$ & $147,25 \pm 7,79$ & $137,37 \pm 2,61$ & $103,78 \pm 7,03$ & $137,50 \pm 7,47$ & $107,32 \pm 4,06$ & $141,03 \pm 4,71$ & $105,80 \pm 6,44$ \\
\hline & $\mathbf{X}_{\mathrm{c}}(\%)$ & 50,3 & 55,2 & 50,6 & 55,2 & 52,3 & 56,6 & 51,6 \\
\hline $\mathbf{T}$ & Ton $(\circ \mathrm{C})$ & $462,32 \pm 0,44$ & $439,11 \pm 1,01$ & $456,73 \pm 1,02$ & $456,46 \pm 0,70$ & $450,81 \pm 2,93$ & $464,32 \pm 0,81$ & $458,51 \pm 1,92$ \\
\hline G & $\begin{array}{c}\text { Mass } \\
\text { loss }(\%)\end{array}$ & $99,77 \pm 0,24$ & $95,83 \pm 0,94$ & $89,40 \pm 0,44$ & $97,53 \pm 0,24$ & $93,63 \pm 1,23$ & $94,91 \pm 0,44$ & $88,92 \pm 0,73$ \\
\hline $\begin{array}{l}\text { D } \\
\text { T } \\
\text { G }\end{array}$ & $T_{\max }(\circ \mathrm{C})$ & $483,76 \pm 0,70$ & $481,39 \pm 0,73$ & $485,39 \pm 1,21$ & $480,68 \pm 1,78$ & $484,84 \pm 0,22$ & $482,21 \pm 0,50$ & $487,53 \pm 1,33$ \\
\hline
\end{tabular}

\section{Mechanical properties}

It is of common knowledge that the interaction between the fiber and the matrix has a significant effect on the mechanical properties of the composites [1]. In order to characterize the mechanical behavior of the cork and polymer composites under study, tensile tests were carried out. Considering the analysis of the stress / strain curves presented in Fig.10 and taking into account the influence of the coupling agent on the properties of the CPC with HDPE, there are two approaches:

- The Fig. 10 a) compares the behavior that the CPC with 15 wt.\% of cork has with the increase of the amount of the coupling agent in the blend. Therefore, the sample with $5 \mathrm{wt} . \%$ of HDPE-g-MA (CPC9) had higher mechanical strength results than the sample of 2 wt.\% (CPC7) and 8 wt.\% (CPC11) of HDPE-g-MA. The addition of a higher percentage of HDPE-g-MA resulted in an increase of the deformation. 
- The Fig. $10 \mathrm{~b}$ ) shows the behavior of cork in the same circumstances, for a concentration of 30 wt. $\%$ of cork in the mixture. Among the samples under study, the sample with addition of $5 \mathrm{wt} . \%$ of HDPE-g-MA (CPC10) is the one with the highest mechanical strength. In relation to the deformation, there were no significant changes between the samples of $2 \mathrm{wt} \%$ (CPC 8 ) and $5 \mathrm{wt} . \%$ (CPC10) of HDPE-g-MA, but between 5 wt.\% (CPC10) and 8 wt.\% (CPC12) an increase is verified. These samples have higher strain rate hardening (though still negative) when compared with 15 wt.\% cork samples.
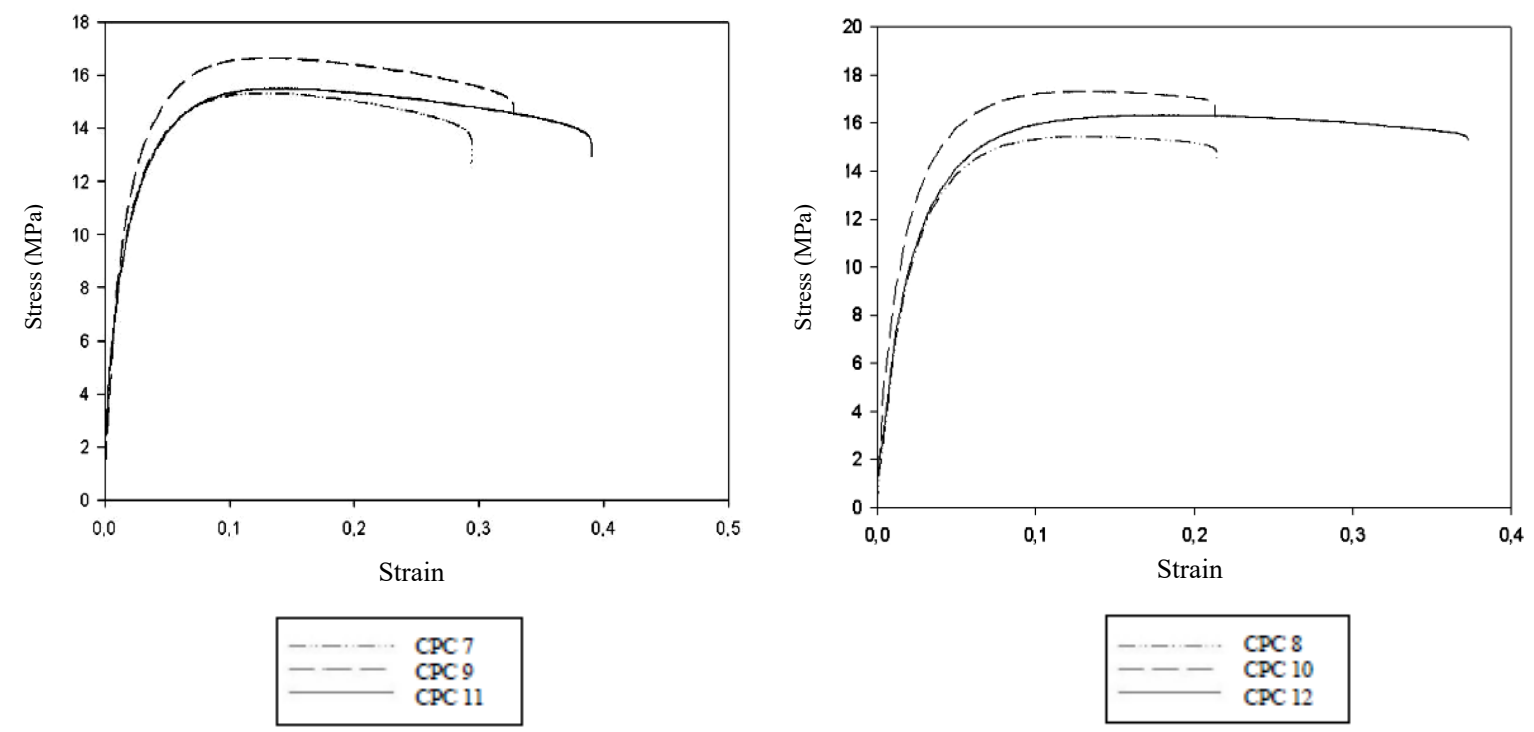

Fig. 10. HDPE CPCs stress / strain curves with coupling agent variation for (a) 15 wt.\% of cork (b) 30 wt. $\%$ of cork

Then, considering the stress / strain curves of the CPC graphs with PP shown in Fig. 11, and taking into account the influence of the coupling agent, a relation also can be established:

- Fig. 11 a) compares the CPC with 15 wt.\% of cork behavior while increasing the amount of PP-g$\mathrm{MA}$ in the blend. From what we can see, there is no significant difference among the samples even though the sample corresponding to the addition of 5 wt.\% of PP-g-MA (CPC3) has slightly higher tensile strength results. In relation to the deformation, the sample with $8 \mathrm{wt} . \%$ of PP-g-MA (CPC5) presented the best results. This behavior proves that the increase in tensile strength is not proportional to the increase of the coupling agent [2], since the use of $8 \mathrm{wt} \%$ of PP-g-MA did not promote an increase in mechanical resistance, compared to the CPC with 5 wt.\% PP-g-MA.

- Fig. $11 \mathrm{~b}$ ) shows the behavior of cork in the same circumstances for a concentration of $30 \mathrm{wt} \% \mathrm{of}$ cork in the mixture. In this particular case, the stress did not vary significantly with increasing concentration of coupling agent in the blend. In relation to the deformation, the sample with 8 wt. $\%$ of PP-g-MA (CPC6) showed a slight increase compared to the sample with $5 \mathrm{wt} . \%$ of PP-g-MA (CPC4). It can be concluded that, in this specific case, the use of a percentage of PP-g-MA of 8 wt.\% seems to improve the mechanical characteristics of the composite. On the other hand, the addition of $2 \% \mathrm{wt} . \%$ of PP-g-MA (CPC2) resulted in a much lower deformation. 

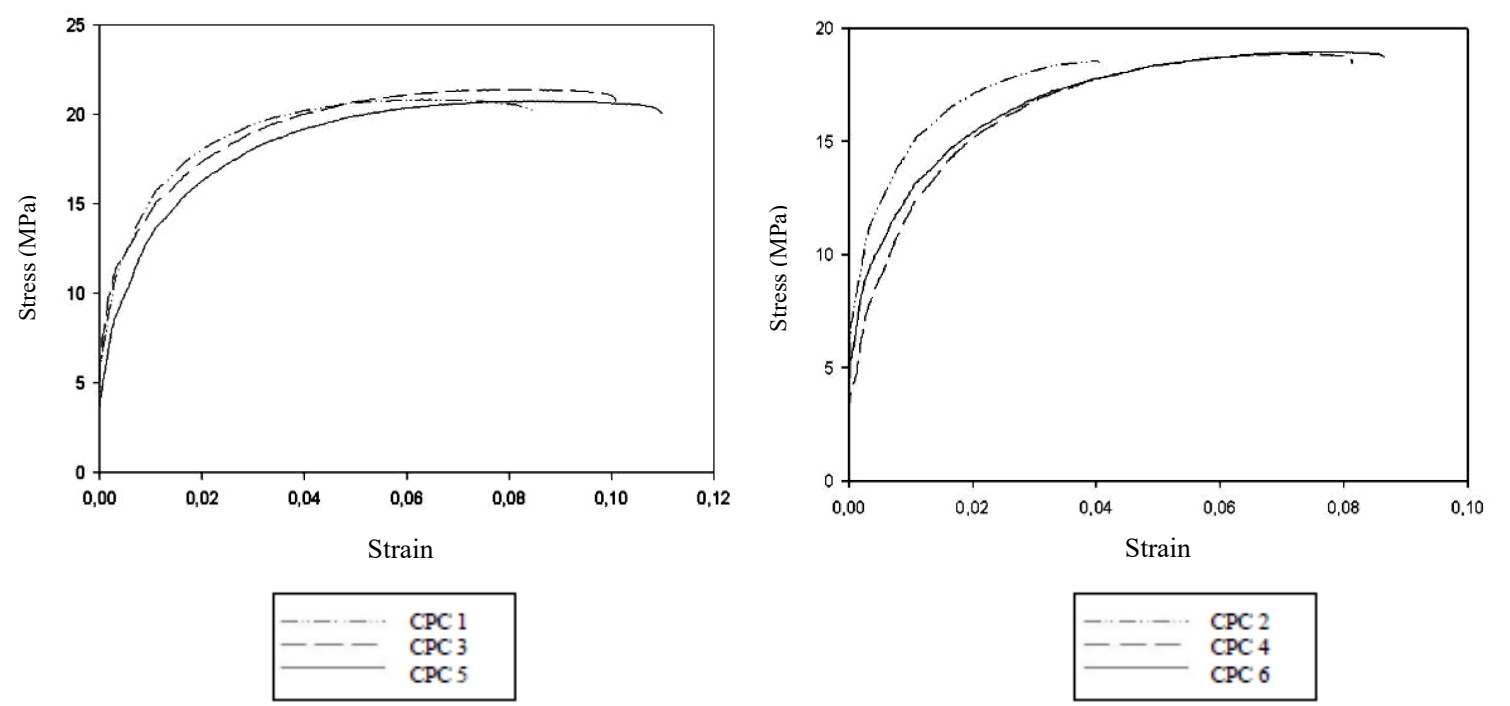

Fig. 11. PP CPCs stress / strain curves with coupling agent variation for (a) $15 \mathrm{wt} . \%$ of cork (b) 30 wt. $\%$ of cork

Finally, a comparison between the mixtures that presented better mechanical properties of the CPCs under study, with a polymer matrix of HDPE and PP was made:

- Fig. 12 a) shows the behavior of CPCs with 15 wt.\% of cork, with HDPE and PP polymer matrix. We can note that there is a significant difference between CPCs. The CPC with PP (CPC3) exhibits a superior resistance, but on the other hand the deformation is smaller.

- Fig. 12 b) shows the CPC behavior for $30 \mathrm{wt} . \%$ of cork. The conclusions that can be drawn from the analysis of the graph are similar with those drawn for CPCs with $15 \mathrm{wt} . \%$ of cork.
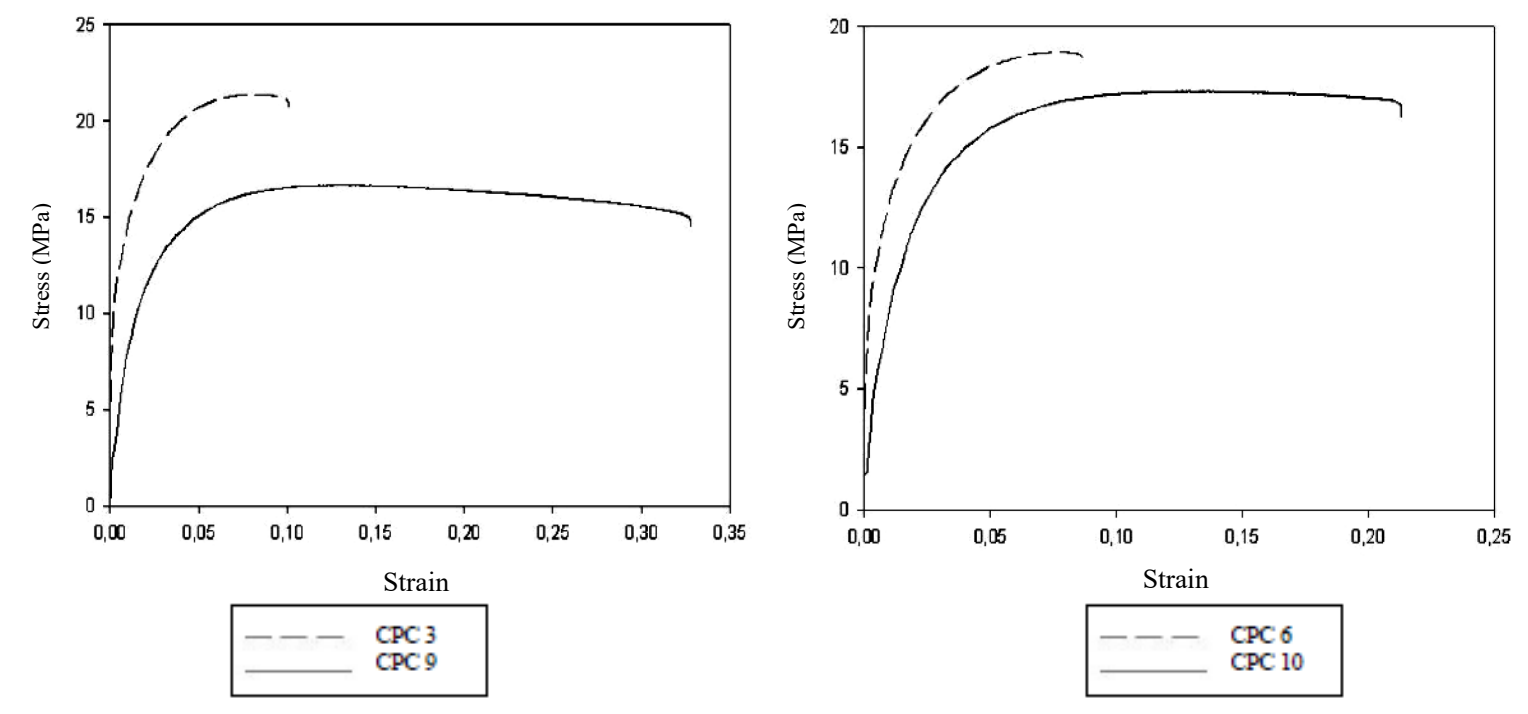

Fig. 12. HDPE and PP CPCs stress / strain curves with coupling agent variation for (a) $15 \mathrm{wt} . \%$ of cork (b) 30 wt.\% of cork

Table 5 summarizes the relevant results obtained in the tensile tests:

- Tensile strength and maximum deformation were significantly reduced in all CPCs compared to the pure HDPE and PP polymers. The decrease in tensile strength may be partly due to the poor adhesion between the cork powder and the matrix, which limits the applied load, resulting in a decrease in tensile strength. 
- Comparing CPCs with pure polymers in terms of modulus of elasticity it is possible to observe a decrease in the case of HDPE CPCs. CPCs with PP did not show significant variation.

- CPC specimens, in general, showed an evident correlation between stress and strain data. For the CPCs with polymeric matrix of PP, with the increase of the percentage of cork from $15 \mathrm{wt} . \%$ to 30 wt.\%, there was a decrease in tensile strength and a decrease in deformation. Regarding the modulus of elasticity, no significant variation was verified. This behavior is in accordance with that obtained by Fernandes et al. [1]. However, CPCs with HDPE showed a different behavior. Besides the CPC9 and CPC10, where the increase of the cork concentration did not provide a significant variation of the tensile strength, in the other composites the tensile strength varied according to the rate of coupling agent added to the composite. Regarding the modulus of elasticity, such as in CPCs with PP, no significant change was observed.

- In general, CPC composites with PP showed better tensile strength results than the HDPE CPCs, but lower deformation.

Table 5. Tensile properties of HDPE, PP and CPCs

\begin{tabular}{llll}
\hline Materials & Strain at break(\%) & Tensile Strength(MPa) & Elastic Modulus(MPa) \\
& & & \\
\hline PP & - & $24.66 \pm 0.28$ & 1500 \\
HDPE & - & $24.30 \pm 0.09$ & 850 \\
CPC1 & $9.01 \pm 0.64$ & $20.76 \pm 0.05$ & $1552.82 \pm 297.64$ \\
CPC2 & $4.85 \pm 1.27$ & $18.48 \pm 0.50$ & $1542.90 \pm 153.13$ \\
CPC3 & $10.17 \pm 0.98$ & $21.32 \pm 0.11$ & $1750.60 \pm 315.92$ \\
CPC4 & $8.23 \pm 0.23$ & $18.82 \pm 0.08$ & $1360.25 \pm 230.90$ \\
CPC5 & $11.07 \pm 0.79$ & $20.64 \pm 0.09$ & $1632.28 \pm 190.05$ \\
CPC6 & $8.67 \pm 1.11$ & $18.96 \pm 0.05$ & $1589.50 \pm 130.80$ \\
CPC7 & $29.75 \pm 3.71$ & $15.35 \pm 0.13$ & $456.14 \pm 24.04$ \\
CPC8 & $31.32 \pm 2.46$ & $16.8 \pm 0.14$ & $528.43 \pm 82.02$ \\
CPC9 & $39.06 \pm 3.00$ & $15.48 \pm 0.29$ & $484.69 \pm 55.92$ \\
CPC10 & $22.00 \pm 0.73$ & $15.36 \pm 0.26$ & $530.74 \pm 49.01$ \\
CPC11 & $21.16 \pm 1.60$ & $17.28 \pm 0.11$ & $520.36 \pm 29.44$ \\
CPC12 & $38.52 \pm 2.26$ & $16.34 \pm 0.23$ & $542.51 \pm 37.80$ \\
\hline
\end{tabular}

\section{D Printing}

For the development of the initial 3D printing tests, a one-piece CAD model was developed for testing (Fig. 13 a)). The piece developed consisted of a base with a square profile that, as it increases its height, it will be rotating progressively in angles of 2 degrees.

Based on the tests previously performed to the CPC, one of the composites studied was chosen, in this case the CPC3. An experimental test was initially performed only to test the material processing. Once the Robot extrusion nozzle comes with a $5 \mathrm{~mm}$ diameter, the test was done for this filament outlet diameter.

For printing the parts a heated base with temperature controllers was used. This base was used in such a way that an ideal temperature could be defined for the construction of the base of the part to prevent warping of the material. This warping occurs because of the temperature difference between the base of the material and the temperatures at which the material is extruded. 

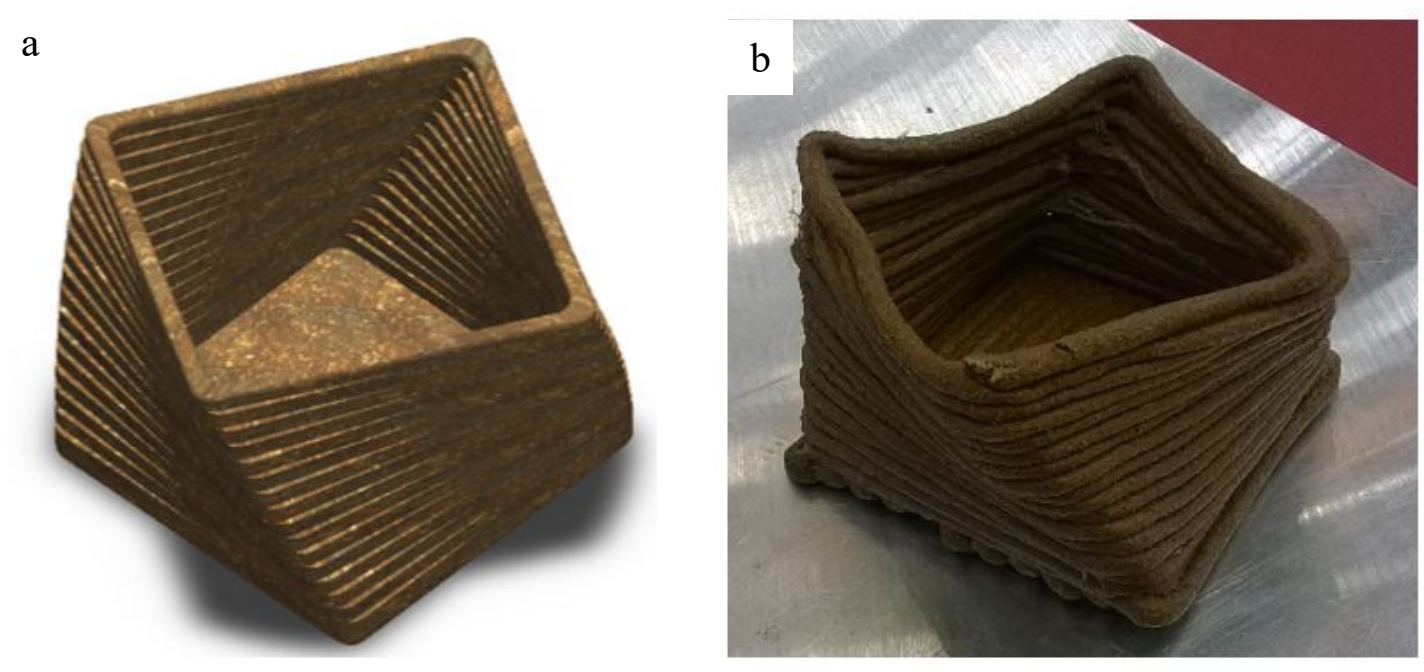

Fig. 13. 3D printing: a) CAD model b) Printed piece

Concerning the final piece obtained (Fig. 13 b)), there are some important considerations that should be highlighted. As had been anticipated, it was necessary to optimize the parameters used in the processing, but in addition there was a structural change. The base was increased and the distance between layers had to be decreased. Several parameters had to be tested during the 3D printing process. After some tests and varying the different parameters, the following was used: extrusion temperature of $165^{\circ}$, air temperature of $50^{\circ}$, heated base platform at $60^{\circ}$ and the extrusion speed was programmed with $500 \mathrm{~mm} / \mathrm{min}$ for the base, $400 \mathrm{~mm} / \mathrm{min}$ for the first 4 layers and $450 \mathrm{~mm} / \mathrm{min}$ until the end of the piece. Even though the piece did not quite reach the optimal printing, it was mainly due to the limitations of the use of the equipment. Changes were necessary in the heated base with the addition of adhesive tape in order to facilitate the stabilization of the material, so that it would not be dragged with the movement of the extruder. The extruder air outlet presented another problem once it was directed in only one direction, not allowing the cooling of the filament evenly. Limitations in tip geometry may have influenced some material entrainment too.

In general, comparing the obtained results, we can say that, even with some difficulties of processing and optimization of parameters, we obtained a piece quite close to what was expected. Both the base and the layers were printed with good finishing and without great differences in relation to the programmed route.

\section{Conclusions}

The objectives of this work consisted on the realization of several combinations of plastic matrices, namely polypropylene (PP) and high density polyethylene (HDPE) obtained from conventional suppliers, and cork powders obtained from the cork processing industries, in order to find an optimal blend for 3D printing. The addition of coupling agent and the increase of the cork concentration significantly affected the properties of the composites, which was confirmed by the results of the mechanical tests and validated by SEM image analysis.

Through the FTIR analysis it was possible to observe the influence of the presence of the cork and the polymer in the CPCs. Regarding wettability, all materials under study showed hydrophilic characteristics, which is not surprising due to the type of processing used. CPCs with PP showed opposite results to HDPE CPCs at coupling agent concentrations of $2 \mathrm{wt} . \%$ and $5 \mathrm{wt} . \%$. For $2 \mathrm{wt} . \%$ of PP-g-MA, the wettability decreased with increasing cork concentration, but at $5 \mathrm{wt} \%$ of PP-gMA increased. Micro-CT analysis showed that the type of processing used, whether extrusion or injection, has a significant impact at the structural level in the composite. This conclusion could be 
validated through SEM analysis where it was generally possible to find a better interaction between the phases in the injection-processed composites, largely due to more efficient compaction.

The thermal properties of the composite materials made from HDPE and PP matrix showed different results. CPCs with PP showed a decrease in crystallinity and an increase in degradation temperature over pure PP. The increase in coupling agent concentration, in general, decreased crystallinity. Regarding HDPE CPCs, a slight increase in crystallinity and earlier onset of chemical degradation were observed, than in pure HDPE. The increase in the coupling agent content did not influenced significantly the crystallinity, however the increase in the cork concentration decreased material crystallinity.

Based on the mechanical tests results, it was possible to conclude that tensile strength and maximum deformation were significantly reduced in all CPCs when compared to those obtained for the pure HDPE and PP polymers. The addition of coupling agent in both composites (HDPE and PP) altered the deformation but did not significantly alter the tensile properties. In the case of CPCs with polymeric matrix of PP, in general, with the increase of the cork concentration, a reduction of the tensile strength and a decrease of the deformation were verified. In the case of HDPE CPCs, the behavior was not linear. In general, the composites with polymeric matrix of PP presented better mechanical results since the polymer matrix of the PP itself is more resistant than those verified for the HDPE.

Printing of the composite was performed with a reasonable quality. Although some constraints related to the printer's own processing parameters and limitations had been overcome, it was not possible to obtain a piece with a perfect finish. Also, it was demonstrated the possibility of printing this type of materials which undoubtedly contributes to a new wave of added value products from composite materials reinforced with natural fibers. Cork, due to its extraordinary properties, represents a truly promising material. Combined with 3D printing, which in turn is an emerging and exponentially growing technology, cork and its derivatives will play a key role in the development of new products.

\section{Acknowledgements}

This work is supported by the Fundação para a Ciência e a Tecnologia (FCT) and Centro2020 through the Project references: UID/Multi/04044/2013 and PAMI - ROTEIRO/0328/2013 (N 022158). In addition, the authors acknowledge the funding from the project World of Outstanding Wool and Wood (WOWW), POCI-01-0247-FEDER-017574 from the Portuguese National Innovation Agency. The authors gratefully acknowledge to Amorim Cork Composites for the cork powder. We thank Ana O. Tojeira and Ana R. Fonseca for the support provided in performing the laboratorial tests as Laboratory Managing Engineers.

\section{References}

[1] E. Fernandes, V. Correlo, J. Mano, R. Reis, Polypropylene-based cork-polymer composites: Processing parameters and properties, Composites: Part B 66 (2014), pp. 210-223.

[2] E.M. Fernandes, New Functionalization / Reinforcement Strategies for Cork Plastics Composites: Opening a wide Range of Innovative Applications for Cork based Products, PhD Thesis, University of Minho, Braga, 2013.

[3] E. Fernandes, I. Aroso, J. Mano, J. Covas, R. Reis, Functionalized cork-polymer composites (CPC) by reactive extrusion using suberin and lignin from cork as coupling agents, Composites Part B: Engineering, 67 (2014), 371-380.

[4] E. Fernandes, V. Correlo, J. Chagas, J. Mano and R. Reis, Cork based composites using polyolefin's as matrix: Morphology and mechanical performance, Composites Science and Technology 70 (2010), pp. 2310-2318. 
[5] S. Silva, P. Lima. J. Oliveira, Rheological behaviour of cork-polymer composites for injection moulding, Composites Part B: Engineering 90 (2015), pp.172-178.

[6] H. Pereira (1992), The thermochemical degradation of cork, Wood Sci.Technol. (1992) 26: 259.

[7] M. Pan, Method for evaluating the wettability of polyethylene against different surfaces at processing temperatures, MSc Thesis, Chalmers University of Technology, Gothenburg- Sweden, 2010.

[8] A. Şen, A. Marques, J. Gominho and H. Pereira, Study of thermochemical treatments of cork in the $150-400^{\circ} \mathrm{C}$ range using colour analysis and FTIR spectroscopy, Industrial Crops \& Products (2012), 38132-138. doi:10.1016/j.indcrop.2012.01.018.

[9] N. Stark and L. Matuana, Surface chemistry changes of weathered HDPE/wood-flour composites studied by XPS and FTIR spectroscopy, Polymer Degradation and Stability 86.1 (2004): 1-9.

[10] N. Stark and L. Matuana, Characterization of weathered wood-plastic composite surfaces using FTIR spectroscopy, contact angle, and XPS, Polymer Degradation and Stability 92.10 (2007): 1883-1890.

[11] S. Silva, P. Lima and J. Oliveira, Non-isothermal crystallization kinetics of cork-polymer composites for injection molding, Journal of Applied Polymer Science (2016), 133(42). 